Www.jmscr.igmpublication.org

Impact Factor (SJIF): 6.379

Index Copernicus Value: 79.54

ISSN (e)-2347-176x ISSN (p) 2455-0450

crossrefDOI: https://dx.doi.org/10.18535/jmscr/v6i8.16

Journal Of Medical Science And Clinical Research

\title{
To Study the Prognostic Factors and Management of Peritonitis
}

Authors

\section{Dr Y Tej Kumar ${ }^{1}$, Dr Narendranath Swain ${ }^{2^{*}}$, Dr Supreet Kumar ${ }^{3}$} Dr Manindra Nayak ${ }^{4}$, Dr Jateen Anshuman ${ }^{5}$

${ }^{1,2}$ Associate Professor, Department of Surgery, SCB Medical College Cuttack, Odisha, India

${ }^{3,4,5}$ Junior Resident, Department of Surgery, SCB Medical College, Cuttack, Odisha, India

*Corresponding Author

Dr Narendranath Swain

Associate Professor, Department of Surgery, SCB Medical College Cuttack, Odisha, India

\section{Abstract}

Aim: To study the validity of scoring system, presently being studied worldwide.

These are:

a. Mannheim peritonitis index.

b. Sepsis score of Elebute and Stoner.

To study the prognostic factor which determine the outcome of the disease.

Materials and Methods: All patients diagnosed with peritonitis and admitted to SCB MEDICAL COLLEGE \& HOSPITAL, Surgical Ward or who developed features of peritonitis due to various causes after being admitted between the period of August 2014 to July 2016.

Total number of cases studied - 100.

Observation: Duodenal perforation formed $73 \%$ (73) of the patients and 68\% (27) of mortality. They had mortality rate of 33\%. Both MPI and Sepsis score accurately predicted mortality and morbidity rates, patients whose MPI was $\leq 26$ had low mortality rate of $7 \%$ whose MPI was $>26$ had nearly $86 \%$ which was statistically significant $(P<0.001)$. Similarly sepsis score of $\leq 20$ had mortality of $7 \%$, score $>20$ had mortality rate of $80 \%(P<0.001)$.

Conclusion: There is wide scope for use of Mannheim peritonitis index, sepsis score of Elebute and Stoner in present context.

Keywords: Mannheim, sepsis score of Elebute, peritonitis.

\section{Introduction}

With the advances that are being made in many areas of medicine, the surgeon must be familiar with infectious diseases of the peritoneal cavity which has increased in severity and complexity. ${ }^{1}$ In addition to the surgical management of secondary peritonitis from gastro intestinal perforation, the practicing surgeon maybe called in to manage patient with cirrhosis with infected ascitic fluid as well as patient undergoing peritoneal dialysis with infected dialysis fluid. ${ }^{2,3}$ In addition, there is increasing recognition of a group of patients with persistent intra-abdominal sepsis or tertiary peritonitis in whom infection is associated with multiple system organ failure and general depression of immune system., ${ }^{4,5}$ Peritonitis continues to be one of the major problems confronting the surgeons. Despite the 
many advances in anti microbial agents and supportive care, the mortality rate of diffuse suppurative peritonitis remains unacceptably high. Its causes vary from the one requiring immediate surgical intervention to that requiring conservative management. Its accurate diagnosis and management is a challenge to every surgeon. ${ }^{6,7}$

The complex nature of surgical infections, the multifaceted aspects of treatment, and the increasing complexity of ICU support make evaluation of new diagnostic and therapeutic advances in this field very difficult. ${ }^{8}$ Scoring systems that provide objective descriptions of the patient's conditions at specific points in the disease process aid our understanding of these problems. This is important in determining the course; the disease is taking in a particular patient, whether the line of management taken is appropriate or need to be changed. ${ }^{9}$

The management of patients with peritonitis has taken a new turn with the understanding of pathophysiologic basis of the disease, the concept of sepsis syndrome and multiorgan failure. The current trend is to recognize these at the earliest and institute aggressive therapy. When the patient has already gone into multi-organ failure, the outlook appears dismal whatever the line of management is. It is here that conservative line of management, as well as newer modalities of treatment such as programmed re laparotomy, immuno modulation is being tried. Although the newer modalities may be useful, they are expensive. Hence, proper clinical monitoring with optimum number of investigations remain the corner stone of emergency surgery and also for the better use of above methods. ${ }^{10}$

The pertinent questions like does the etiology of peritonitis influence the outcome? Do delays in presentation matter? Could this patient been better off without surgery? Continue to dog the minds of most surgeons. I seek to find answers to some of these through this study.

\section{Aims \& Objectives}

1. To study the validity of scoring system, presently being studied worldwide.
These are:

a. Mannheim peritonitis index.

b. Sepsis score of Elebute and Stoner.

c. APACHE - II

2. To study the prognostic factor which determine the outcome of the disease.

These are:

a. Patient factors:-

- Age of the patient

- Sex of the patient.

- General health of the patient like Nutrition, Anaemia.

b. Disease process

- Site of perforation

- Duration of perforation

- The extent of peritoneal contamination.

c. Effect of General systemic complications like

- Respiratory

- CVS system

- Shock

- Multi-organ failure

The aim was to study the effect of above factors on Mortality and morbidity of the patients.

\section{Materials \& Methods}

All patients diagnosed as peritonitis and admitted to SCB MEDICAL COLLEGE \& HOSPITAL, Surgical Ward or who develop features of peritonitis due to various causes after being admitted between the period August 2014 to July 2016.

\section{Methodology}

The study being prospective study, all patients admitted to surgical wards as above were considered according to inclusion and exclusion criteria.

\section{Definitions employed for study}

1. Peritonitis: acute suppurative inflammation of the peritoneal cavity, arising as a consequence of primary disease of the abdominal hollow visceral perforation, of blunt or penetrating trauma or operation within the peritoneal spaces. 
2. Shock: Clinical sign of reduced peripheral perfusion and any two of the following

- systolic B.P. of no more than 90 $\mathrm{mmHg}$

- heart rate of at least 100 beats per minute

- Urine output of less than $80 \mathrm{ml} / 4$ hrs

- Use of pressors to maintain BP for at least $\geq 1 \mathrm{hr}$.

3. Multiple organ failure: - Failure of any two or more of the following system.

I. Renal:

Blood urea $\geq 50 \mathrm{mg} / \mathrm{dl}$. And / or serum creatinine $\geq 2 \mathrm{mg} / \mathrm{dl}$.

II. Hepatic

Serum bilirubin $\geq 2 \mathrm{mg} / \mathrm{dl}$

III. Lung: - 5 or more days of ventilator support. Or $\mathrm{PO} 2<50 \mathrm{~mm} \mathrm{Hg}, \mathrm{PCO} 2>$ $50 \mathrm{mmHg}$ Or F1O2 $\geq 0.4$

IV. Shock

V. Intestinal obstruction - Profound paralytic ileus $\geq 24 \mathrm{hr}$.

4. Day 1 - date of entry into a study, the day on which the diagnostic of peritonitis made and specific treatment, medical or surgical instituted.

\section{Parameters measured}

Risk satisfaction of above selected patients as below:

a. Clinical judgments - using proforma

b. Severity index from model below 31

GeneralParameter

Disease- Diagnosed using clinical imaging

Techniques, operative finding (if any) as confirmatory evidence.

Disease process- Type of perforation

Severity- Alteration in physiology studied using

Scoring systems - Mannheim peritonitis index (MPI) and sepsis score of Elebute and Stoner and evidence of shock.

Concurrent Disease- Cancer, Diabetes Mellitus, Cardiac, etc.

Physiological reserve- Age, functional states.
Response to treatment- Change in physiology

Sample Size

Total number of causes studied - 100

\section{Inclusion Exclusion Criteria}

All patients who satisfied above diagnostic criteria were included in the study.

\section{Exclusion Criteria}

Patients with gynaecological peritonitis, biliary peritonitis, postoperative peritonitis were excluded from the study.

\section{Results}

Patients with peritonitis admitted in SCB Medical College \& Hospital were studied from August 2014 to July 2016; total number cases studied were 100.

\section{(i) Study of Patient factors}

Age: The patients with age ranging from 17 years - 75 years were studied. Maximum number of patients were in Middle age (31-50 years)- 43 patients. But the mortality rate was more in extremes of age that is $\leq 20$ years $>50$ years group. The mortality rate of elderly patient was $100 \%$ (1 patient)

Sex: Maximum number of patients were male 90 , but mortality rate was more in females $(40 \%)$. Since maximum patients were male, the number of deaths was more in males.

\section{(ii). Study of disease process}

\section{Mortality $v / s$ time of presentation}

The time of presentation of patients ranged from $<24$ hours to $>12$ days. Maximum patients presented in 1-3 days $(41 \%)$. Mortality increased correspondingly with delay in perforation. It was $5 \%$ for <24hours, $88 \%>9$ days, and $100 \%$ for more than 9days. 
Tabel 1

Table 2

\begin{tabular}{|l|c|c|c|}
\hline Age & Survived & Died & Total \\
\hline$<20$ & $6(60 \%)$ & $5(40 \%)$ & 11 \\
& $(10 \%)$ & $(12 \%)$ & $(11 \%)$ \\
\hline $21-30$ & $17(81 \%)$ & $6(19 \%)$ & 23 \\
& $(29 \%)$ & $(12 \%)$ & $(23 \%)$ \\
\hline $31-40$ & $13(20 \%)$ & $6(30 \%)$ & 19 \\
& $(21 \%)$ & $(10 \%)$ & $(19 \%)$ \\
\hline $41-50$ & $15(62 \%)$ & $9(33 \%)$ & 24 \\
& $(24 \%)$ & $(22 \%)$ & $(24 \%)$ \\
\hline $51-60$ & $6(48 \%)$ & $9(52 \%)$ & 15 \\
& $(11 \%)$ & $(22 \%)$ & $(15 \%)$ \\
\hline $61-70$ & $3(40 \%)$ & $4(60 \%)$ & 7 \\
& $(5 \%)$ & $(4 \%)$ & $(7 \%)$ \\
\hline$>71$ & 0 & $1(100 \%)$ & 1 \\
& & $(4 \%)$ & $(1 \%)$ \\
\hline Total & $60(60 \%)$ & $40(40 \%)$ & 100 \\
& $(100 \%)$ & $(100 \%)$ & $(100 \%)$ \\
\hline
\end{tabular}

\begin{tabular}{|l|c|c|c|}
\hline Age & Survived & Died & Total \\
\hline Male & $54(65 \%)$ & $36(35 \%)$ & 90 \\
& $(90 \%)$ & $(82 \%)$ & $(90 \%)$ \\
\hline Female & $6(60 \%)$ & $4(40 \%)$ & 10 \\
& $(10 \%)$ & $(12 \%)$ & $(10 \%)$ \\
\hline Total & $60(60 \%)$ & $40(40 \%)$ & 100 \\
& $(100 \%)$ & $(100 \%)$ & $(100 \%)$ \\
\hline
\end{tabular}

As most patients presented in 1st week, maximum number of mortality concentrated in this region29(74\%).

\section{Mortality Vs type of perforation}

Perforations were grouped into 8 etiologies. Duodenal perforation was the commonest cause (73\%) followed by enteric and Tubercular. The mortality rate of Duodenal perforation, tubercular and traumatic were similar at 33 while enteric was
$40 \%$. Malignant perforation had $100 \%$ mortality, while perforation of the stomach had lowest $14 \%$ mortality; none of the stomach perforations were malignant.

\section{Effect of shock on mortality}

As many as 54 patients (54\%) presented with shock on day 1 . They had high mortality of 34 $(58 \%)$ in comparison to $6(12 \%)$ in patients without shock.

\section{Table 3}

\begin{tabular}{|l|c|c|c|}
\hline Age & Survived & Died & Total \\
\hline$<24$ Hrs. & $\begin{array}{c}28(95 \%) \\
(46 \%)\end{array}$ & $\begin{array}{c}3(5 \%) \\
(4 \%)\end{array}$ & $\begin{array}{c}31 \\
(31 \%)\end{array}$ \\
\hline $24-72$ Hrs. & $26(67 \%)$ & $15(33 \%)$ & 41 \\
& $(43 \%)$ & $(38 \%)$ & $(41 \%)$ \\
\hline $4-6$ days & $5(31 \%)$ & $6(69 \%)$ & 19 \\
& $(9 \%)$ & $(36)$ & $(19 \%)$ \\
\hline $7-9$ days & $1(18 \%)$ & $14(69 \%)$ & 19 \\
& $(2 \%)$ & $(36 \%)$ & $(19 \%)$ \\
\hline $10-12$ days & 0 & $1(100 \%)$ & 1 \\
& & $(2 \%)$ & $(1 \%)$ \\
\hline$>12$ days & 0 & $1(100 \%)$ & 1 \\
& & $(2 \%)$ & $(1 \%)$ \\
\hline Total & $(60 \%)$ & $(40 \%)$ & 100 \\
& $(100 \%)$ & $(100 \%)$ & $(100 \%)$ \\
\hline
\end{tabular}


Table 4

\begin{tabular}{|l|c|c|c|}
\hline Etiology & Survived & Died & Total \\
\hline Duodenal & $46(63 \%)$ & $27(23 \%)$ & 73 \\
Perforation & $(76 \%)$ & $(68 \%)$ & $(73 \%)$ \\
\hline Enteric & $4(60 \%)$ & $3(40 \%)$ & 7 \\
Perforation & $(7 \%)$ & $(8 \%)$ & $(7 \%)$ \\
\hline Tubercular & $2(67 \%)$ & $2(33 \%)$ & 4 \\
Perforation & $(4 \%)$ & $(4 \%)$ & $(4 \%)$ \\
\hline Traumatic & $2(67 \%)$ & $2(33 \%)$ & 4 \\
Perforation & $(4 \%)$ & $(4 \%)$ & $(4 \%)$ \\
\hline Malignant & 0 & $2(100 \%)$ & 2 \\
Perforation & & $(6 \%)$ & $(2 \%)$ \\
\hline Non-specific Ileal & 0 & $1(100 \%)$ & 1 \\
& & $(4 \%)$ & $(1 \%)$ \\
\hline Stomach & $4(86 \%)$ & $1(14 \%)$ & 5 \\
& $(7 \%)$ & $(2 \%)$ & $(5 \%)$ \\
\hline Others & $2(50 \%)$ & $2(50 \%)$ & 4 \\
& $(2 \%)$ & $(4 \%)$ & $(4 \%)$ \\
\hline Total & $(60 \%)$ & $(40 \%)$ & 100 \\
& $(100 \%)$ & $(100 \%)$ & $(100 \%)$ \\
\hline
\end{tabular}

\section{Table 5}

\begin{tabular}{|l|c|c|c|}
\hline Shock & Survived & Died & Total \\
\hline Shock on day 1 & $20(42 \%)$ & $34(58 \%)$ & 54 \\
& $(33 \%)$ & $(84 \%)$ & $(54 \%)$ \\
\hline No shock on day 1 & $40(88 \%)$ & $6(12 \%)$ & 46 \\
& $(67 \%)$ & $(16 \%)$ & $(46 \%)$ \\
\hline Total & $60(60 \%)$ & $40(40 \%)$ & 100 \\
& $(100 \%)$ & $(100 \%)$ & $(100 \%)$ \\
\hline
\end{tabular}

\section{Discussion}

Peritonitis is a dreaded complication and if not treated in time, can terminate fatally. In our study on 100 patients in Victoria Hospital, we found various factor like age, associated medical illness, shock at the time of admission, and extent of peritoneal contamination as important prognostic factor in the outcome of these patients. The data we obtained were tabulated and percentage calculated wherever necessary, the significance of difference in various groups were calculated using $\chi 2$ test, student-t test and other statistical methods. We have used results obtained from similar other studies to illustrate our point.

\section{Age}

Age seem to be the important factor in determining the outcome. Extremes of age had increased mortality rates. However, when it is divided into different group ranges from $\leq 20,21$ $30,31-40 \ldots \ldots \ldots \geq 71$, the Difference in age group is not statistically significant, when verified using $\chi 2$ test $(\mathrm{p}>0.05)$ The probable explanation could be, the classified age group<20,31-30,41 50 which formed substantial population has similar rates. This is in agreement with studies by Delinger et al. who found difference in mortality indifferent groups as above not statistically significant. To illustrate our point, we further regrouped these in to $\leq 50,>50$ to estimate the significance.

Hence was incorporated in Mannheim peritonitis index where age $>50$ years was given weight age of 5 points of severity.

Table 6

\begin{tabular}{|l|c|c|c|}
\hline Age & Survived & Died & Total \\
\hline$\leq 50$ & $\begin{array}{c}50(71 \%) \\
(84 \%)\end{array}$ & $\begin{array}{c}26(29 \%) \\
(62 \%)\end{array}$ & $\begin{array}{c}76 \\
(76 \%)\end{array}$ \\
\hline$>50$ & $\begin{array}{c}10(42 \%) \\
(16 \%)\end{array}$ & $\begin{array}{c}14(58 \%) \\
(38 \%)\end{array}$ & 24 \\
& 60 & 40 & 100 \\
\hline Total & &
\end{tabular}

Table7

\begin{tabular}{|l|c|c|}
\hline Age & Our Study & Tripathi $^{32}$ \\
\hline Upto40Years & $27 \%$ & $21 \%$ \\
\hline$>$ 40Years & $45 \%$ & $32 \%$ \\
\hline
\end{tabular}


Factors like decreased functional reserve, concomitant other illness such as diabetes, hypertension, and local factor such as malignancy seem to be the cause of increased mortality in elderly patients.

\section{Sex}

As in most studies males outnumber females by 9:1. Mortality rate was higher in females (Table2). This difference is not significant, $(\mathrm{p}<0.05)$ may be because of very less number of females in our study (only 10)

i) Degreeoffreedom:1

ii) Chisquare 0

\section{Study of disease process}

\section{Mortality Vs. time of presentation}

In our study, duration of perforations from the time of presentation seemed to have major impact. From (Table3), it can be seen that mortality for patients presenting within $24 \mathrm{hr}$ was $5 \%$.which it increased to $33 \%$ for $24-72 \mathrm{hrs}$. And up to $100 \%$ for delayed presentation more than 1 week. This is incomplete agreement with the result of most studies.

\section{Table8}

\begin{tabular}{|l|c|c|}
\hline Duration & Our Study & Tripathi $^{11}$ \\
\hline$<3$ days & $20 \%$ & $12.9 \%$ \\
\hline 4-6days & $69 \%$ & $57 \%$ \\
\hline$>$ 7days & $88 \%$ & $75 \%$ \\
\hline
\end{tabular}

Table 9

\begin{tabular}{|l|c|c|}
\hline Duration & Our Study & Dandapatetal $^{12}$ \\
\hline$<24 \mathrm{hrs}$ & $5 \%$ & $<6 \%$ \\
\hline$>72 \mathrm{hrs}$ & $74 \%$ & $80 \%$ \\
\hline
\end{tabular}

On further analysis of the data using $\mathrm{X} 2$ test (30.15) for group data the $\mathrm{P}<0.001$, confirming that the difference in mortality is highly significant. Hence, delay in presentation is associated with corresponding increase in mortality. Degree of Freedom:5. The value of 4points given in MPI is in agreement with this. The spread of peritonitis, shock due to delay, onset of sepsis syndrome. Seem to be the main causes for increase in mortality rate. This has to be weighed against patient factor like age, associated medical problem also. Even after discounting these factors there seem to be definite increase in mortality due to delay in presentation (Svoannes) $^{13}$

\section{Mortality Vs. type of perforations}

As with most studies duodenal perforation from bulk of the cases (73/100). They contributed as much as $68 \%$ to the mortality due to the number of cases itself. They had mortality rate of $33 \%$. Enteric perforation had higher mortality of $40 \%$ delay in presentation, typical clinical features, general complication of typhoid seem to contribute to higher mortality rate (Nair, Bobin)

\section{Table10}

\begin{tabular}{|l|c|c|c|c|c|c|}
\hline Etiology & Our Study & Nair $^{\mathbf{1 4}}$ & Mishra $^{\mathbf{1 5}}$ & Tripathi $^{\mathbf{1 6}}$ & Goligher $^{\mathbf{1 7}}$ & Delinger $^{\mathbf{1 8}}$ \\
\hline Duodenal perforation & $33 \%$ & - & - & $16.6 \%$ & - & $41 \%$ \\
\hline Enteric & $40 \%$ & $48 \%$ & - & $32 \%$ & - & - \\
\hline Tubercular & $33 \%$ & $100 \%$ & $30 \%$ & - & - & - \\
\hline Malignant perforation & $100 \%$ & - & - & - & $71 \%$ & - \\
\hline Traumatic perforation & $33 \%$ & - & - & $33 \%$ & - & - \\
\hline
\end{tabular}

As illustrated in the above table, even though the trend in mortality rate is more or less similar. There is a definite difference in mortality rate among various study. As noted by Delinger, Billing, this wide variation reported among various study is due to variation in selection of cases. Some studies get cases with early presentation, while other may get delayed complicated cases. It is exactly to counter this variation ; risk stratification and scoring systems have been evolved in various groups. As illustrated below, when all the prognostic factors are taken into account, there may not be much difference.MPI considers malignant perforation, contaminant whether clear, purulent or faecal as important factor for mortality, in agreement with this cases where fecal peritonitis occurred (enteric perforation) there was high mortality.

Study done by Farthmann $^{19}$ showed that anatomical origin of bacterial contamination and 
microbiological findings are no major predictor of outcome when, complication like shock, extend of peritoneal contamination, organ failure are considered.

\section{Effect of shock on mortality}

In our study, effect of shock on day1 was associated with significant mortality (58\%) similar to other studies

\section{Table11}

\begin{tabular}{|c|c|c|c|}
\hline & Our study & Dandapat & Delinger et al \\
\hline Shockonday1 & $58 \%$ & $62.5 \%$ & $51 \%$ \\
\hline
\end{tabular}

Shock is systemic manifestation due to loss of fluid electrolytes, septicemia and organ failure. In agreement with most studies, we had high mortality. MPI also gave seven risk points to multi organ failure a culmination of shock and other systemic manifestations.

\section{Study of scorings systems}

\section{a. MPI Score}

MPI score was specifically designed to evaluate prognostic factors in peritonitis. It is easy and reliable (Billing). The results of our study correspond to the study by Billing et al., in the trend.

\section{Table12}

\begin{tabular}{|l|c|c|c|}
\hline Score & Our study & $\begin{array}{c}\text { Billing- } \\
\text { 2000Pts }\end{array}$ & $\begin{array}{c}\text { Billing-at } \\
\text { center four }\end{array}$ \\
\hline$>19$ & $0 \%$ & $0 \%$ & $1 \%$ \\
\hline $20-29$ & $28 \%$ & $24 \%$ & $50 \%$ \\
\hline$>29$ & $80 \%$ & $78 \%$ & $87 \%$ \\
\hline$\leq 26$ & $7 \%$ & $4.3 \%$ & 5.3 \\
\hline$>26$ & $86 \%$ & $41 \%$ & $81 \%$ \\
\hline
\end{tabular}

The minor difference in mortality rate is due to difference in selection criteria as these studies included appendicular perforations, which has better prognosis(Billing),pancreatitis and other non peritonitis. Even then the overall mortality trend is similar. This again validates the MPI score in wide ranging causes of peritonitis and can be used for peritonitis due to various causes. As seen from graph the mortality and survivor varies exponentially with increase in the score.
The difference in mortality between 2 groups $\leq 26,>26$ was statistically very significant by $\mathrm{x} 2$ test $<0.001(\mathrm{x} 2=62.7)$.DOF: 1

\section{b) Sepsis score of Elebute and Stoner.}

Sepsis score, similar to MPI, the mortality rate increased with increase in score. An arbitrary point of 20 was taken as cutoff point. Mortality rate was $7 \%$ for $\leq 20,80 \%$ for $>20$.

\section{Table 13}

\begin{tabular}{|l|c|c|c|}
\hline $\begin{array}{l}\text { Mortality Vs. } \\
\text { Sepsis score }\end{array}$ & Our study & Elebute7 & Dominion \\
\hline$\leq 20$ & $7 \%$ & $9 \%$ & $20 \%$ \\
\hline$>20$ & $80 \%$ & $100 \%$ & $89 \%$ \\
\hline
\end{tabular}

The advantage of sepsis score we found that it can be used both or a single indicator and for follow up. Points are given to postoperative complication like sepsis, deep seated abscess, and fistula so that patient can be monitored continuously. However one important finding was patients conservatively had less sepsis score as score for post-operative wound sepsis, fistula were discounted, hence for these patient's the sepsis score was less compared to MPI. The mortality increase exponentially after the cutoff point (20) The difference in mortality rate is 2 group $(\leq 20,>20)$ was statistically very significant $\mathrm{P}<0.001(\mathrm{x} 2=56.65)$

\section{Study of factors contributing to morbidity}

For each analysis, the factors are divided in to 2groups.

Survivor group

Age $\leq 50$ years, $\mathrm{MPI} \leq 26$, sepsis score $\leq 20$, Perforation duration $\leq 24 \mathrm{hrs}$.

Mortality group:

Age $>50$ years, MPI >26, sepsis score $>20$

(High risk group) Perforation duration $>24 \mathrm{hrs}$.

In our study we found that in survivor group patients tend to have less general complication and less serious local complications conversely, the mortality group had more serious local complications like faecal fistula, deep seated abscess.

This is in agreement with current studies. This paves way to try definitive surgeries for 
perforation in the patients like $\mathrm{TV}+\mathrm{G}$, which is being tried in many centers (Boey, Dandapat) ${ }^{20}$

\section{Table 14}

\begin{tabular}{|l|c|c|}
\hline Complications & Our study & Tripathietal. $^{19}$ \\
\hline Faecal fistula & $7 \%$ & $7.5 \%$ \\
\hline Wound sepsis & $24 \%$ & $26 \%$ \\
\hline MOF & $15 \%$ & $11 \%$ \\
\hline
\end{tabular}

\section{Conclusion}

There is wide scope for use of Mannheim peritonitis index, sepsis score of Elebute and Stoner in present context.

\section{References}

1. Billing A, Frohlich D, Schildberg F.W., Prediction of outcome using the Mannheim peritonitis index in 2003 patients. Peritonitis study group. Br.J.Surg 1994 Feb:81(2):20913.

2. Delinger P.E. etal. Surgical infection stratification system for intra-abdomina linfection. Arch.Surg.1985 Jan;120:21.

3. Pacelli F, etal. Prognosis in intra-abdominal infectins. Multivariate analysis on 604 patients. Arch Surg. 1996 June; 131(6):641-5

4. Durham H. The mechanism of reaction to peritoneal infection. J. Pathol. Bacteriol. 1897;4:338-82.

5. Melaney F.L. Olip J,et al. Peritonitis: II. Synergism of bacteria commonly found in peritoneal exudates. Arch Surg. 1932;25:709.

6. Fry D.E. Garrison R.N. etal. Determinants of death in patients with intra abdominal abscess. Surgery. 1980;88:517.

7. Elebute E.A., Stoner H.B. The grading of sepsis. Br.J.Surg.1983;70:29-31.

8. Pine R.W. Wertz M.J. et.Al. Determinants of organ malfunction or death in patients within tra-abdominal sepsis. Arch Surg.1983; 118:242-249.

9. Stevens L.E. Gauging the severity of surgical sepsis. Arch Surg. 1983;118:1190-1192.
10. Knaus W.A, Draper E.A, Wagner D.P. etal. Prognosis in acute organ system failure. Ann. Surg.1985;202:685-693.

11. Teichmann W. Wittmann D.H, etal. Scheduled reoperations (ettappenlavage) for diffuse peritonitis. Arch. Surg. 1986;121:147152.

12. Wach. H, Linder M.M, etal. Mannheim peritonitis index-prediction of risk of death from peritonitis; construction of astatic and validation of an empirically based index. The oritical Surgery 1987;1:169-77.

13. Kohli V, etal. Evaluation of prognostic factors in perforated pepticulcer. Indian Journal of Surgery. 1988May-June; 50:184.

14. Verma G.R. etal. Gastro-intestinal injuriesin abdominal trauma. Trop Gastroenterol 1990Oct-Dec;11(4):206-10.

15. Demnel N. Muth G.,Maag K., Osterholzer G. Prognostics cores in peritonitis: the Mannheim peritonitis index or APACHEII? Langen becks Arch Chir1994;379(6):347-52.

16. Dumont A.K, Mass W.K, etal. Increased survival from peritonitis after block adeoftrans-diaphragmatic absorption of bacteria. Surg. Gynecol Obstet. 1966;162 $: 248$.

17. Nyhus L.M, Baker R.J, etal. Ed. Master of Surgery, Little Brown and Company. $1997 ; 146$.

18. Nystrom P.O. et al. Joint working party of SISN orth America and Europe. Proposed Definitions for Diagnosis. Severity Scoring, stratification and outcome for trials on intra abdominal infection. World J.Surg.1990; 14:148-158.

19. Tripathi M.D. et al. Peritonitis-study of factors contributing to mortality. Indian Journal of Surgery.1993;55(7):342-349.

20. Dandapat M.C., Mukherjee L.M., Mishra S. B., Howlader P.C. Gastrointestinal perforations. Indian Journal of Surgery, 1991;53 (5):189-93. 